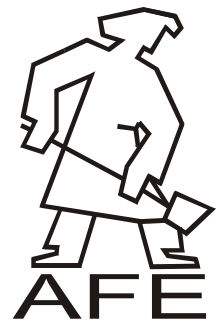

\title{
Usage of Connor Inlets to Eliminate Shrinkage
}

\author{
D. Fecko*, I. Vasková, L. Eperješi, M. Závodný \\ Department of Ferrous Metallurgy and Foundry, Faculty of Metallurgy, Technical University in Košice, Slovakia, \\ *Corresponding author. E-mail address: daniel.fecko@tuke.sk
}

Received 16.04.2012; accepted in revised form 02.07.2012

\begin{abstract}
The demand for castings of high quality and sound work is nowadays very high. The production of sound castings without foundry errors is the big issue in modern foundries. Foundry simulation software can do a lot to help improve the disposition of castings, gating system and feeder system, and assure good filling and solidification conditions, and also produce sound casting without the need of the old method of "try and error". One can easily change a lot of parameters for filling and solidification, and create the best proposal for production. Connor inlets have two functions. One is that it serves as an ingate, through which molten metal passes and comes into the mould cavity. The second function is that it serves as a feeder and substitutes the metal contracted during solidification and cooling of the castings. It can also save quite a lot of metal in comparison to classic feeders.
\end{abstract}

Keywords: Gray cast iron; Connor inlet, Shrinkage elimination; Simulation software

\section{Introduction}

The casting used for simulation in this article serves as part of a pumping device used in the mining industry. It is produced from gray cast iron, namely GJL-150. On Fig. 1 is shown the casting with the basic dimensions. The weight of this casting is $0,75 \mathrm{~kg}$. There are 12 pieces of the casting on the model pattern. Allocation of castings, gating system and feeder system is shown on Fig. 2. This casting is produced on an automatic moulding line DISAMATIC with vertical joint plane. The pouring time was set to 11 seconds due to a flow of $1,5 \mathrm{~kg} / \mathrm{s}$ according to the pouring device. The pouring temperature was set to $1330^{\circ} \mathrm{C}$.

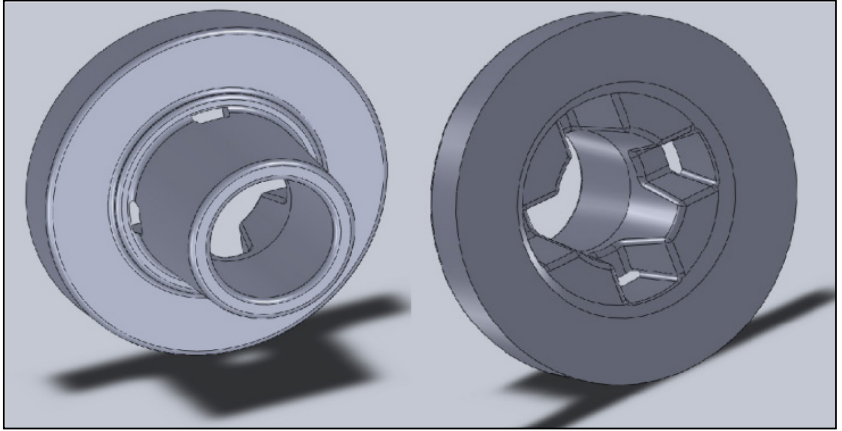

Fig. 1 Simulated casting (diameter $92 \mathrm{~mm}$, height $54 \mathrm{~mm}$, diameter of the hole $33 \mathrm{~mm}$ ) 


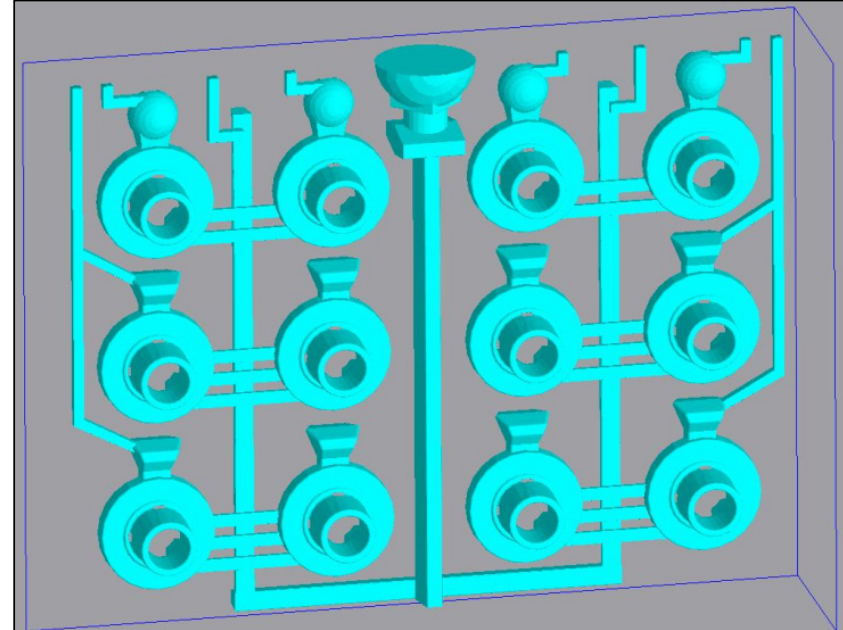

Fig. 2 Allocation of castings, gating system and feeder system

The simulation software used for simulation of this casting was NovaFlow\&Solid CV 4.4r6. This software was developed by the company NOVACAST, Sweden. It is based on the control volume method, which is one of the most commonly used and according to the producer, it is one of the fastest simulation software [1].

\section{Experiments}

The aim of this work is to consider the suitability of the proposed allocation of castings, gating system and feeder system. If it is necessary, the changes of the gating system or the feeder system must be done.

As first version, the proposed allocation (see Fig. 2) was simulated. For the first simulation, the mesh was created with a cell size of $4,3 \mathrm{~mm}$, which means that in the mould is 533664 cells, from which 47100 cells belong to the metal part of the mould (castings, gating system, feeder system). Simulation was set for both filling and solidification - module FLOW\&SOLID. After finishing the simulation, it was noticed that the filling of the mould cavity ran smoothly, without any splashes of molten metal. The process of filling is described in Fig. 3 [2].

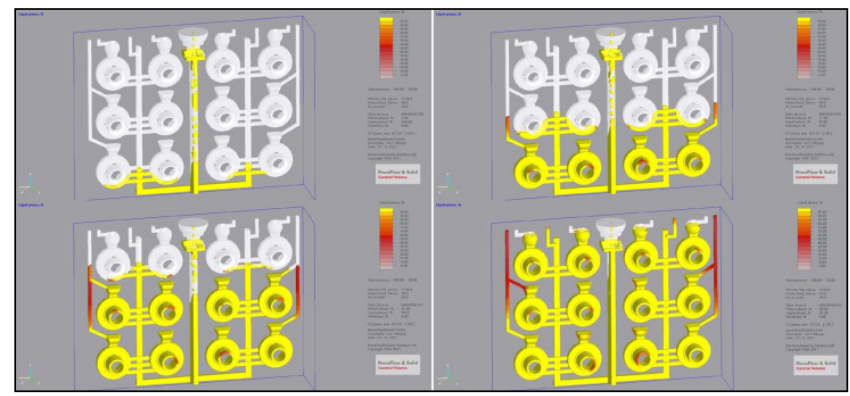

Fig. 3. Process of mould cavity filling

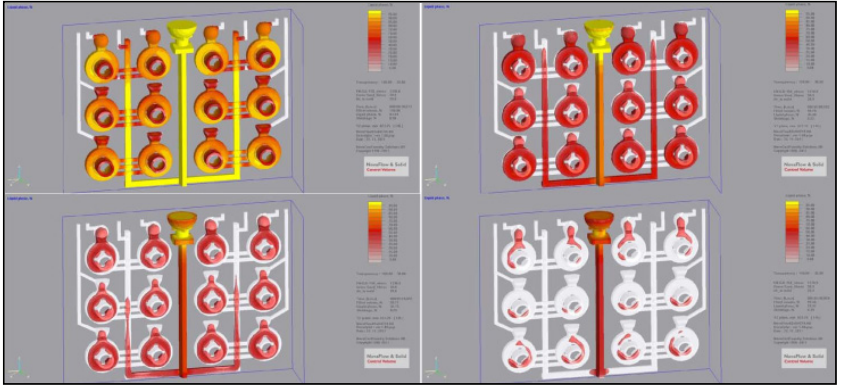

Fig. 4. Process of solidification of the molten metal

As it is obvious from Fig. 4, solidification goes from outside the castings to the centre of the casting. For the four upper castings, the feeder with diameter of $40 \mathrm{~mm}$ is enough, the last molten metal solidifies in this feeder. On the other hand, the different shape of the feeders in the middle and lower rows (due to a lack place on the model pattern) is not sufficient to substitute the contracted molten metal in the castings. In these places, the last molten metal does not solidify in the feeder, but it solidified last in the castings which means that foundry defects should occur there, mainly shrinkage. To prove this statement, on the Fig. 5 is shown the allocation of shrinkage after solidification and cooling. As it can be seen, the upper castings are without any defects. But in the middle and lower row castings, shrinkage can be noticed very clearly. The red markings represent the shrinkage. From the scale on the right side how much of the metal is missing in the places where shrinkage occurs can be determined,

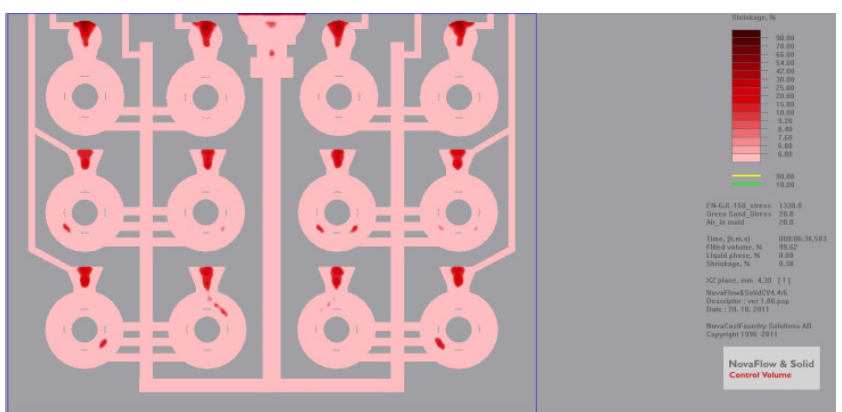

Fig. 5. Distribution of shrinkage in the castings and feeders (cross-section)

The occurrence of the shrinkage in the castings can be seen also in the cross-section of the produced casting, Fig. 6. 

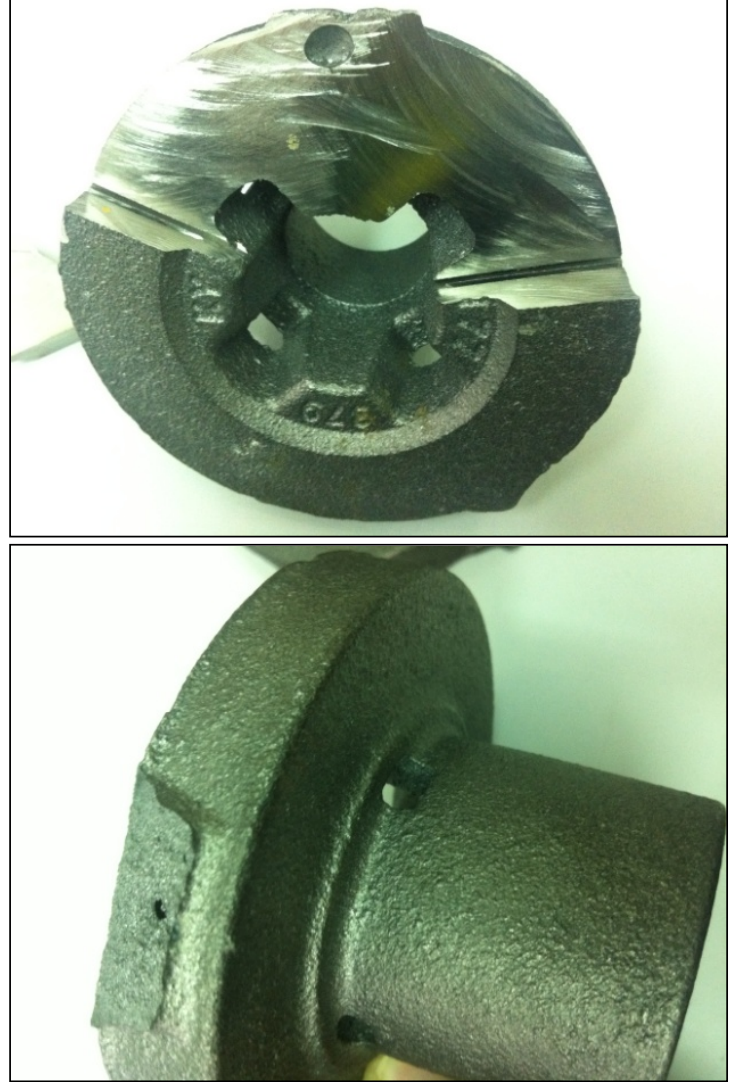

Fig. 6. Shrinkage in the cross-section of the casting and under the feeder

Due to the bad course of solidification (the last molten metal does not solidify in the feeders but in the casting) the hot spots are located in the castings and not in feeders, other version must have been done.

In order to replace the hot spots to the feeder, it was needed to change the gating system and feeder system. The ingates and feeders from the previous version were replaced by Connor inlets (serving as an ingate and also as a feeder). Few versions of the shape and dimensions were simulated to meet the desired design of Connor inlet. Only the last version which was also proposed to technologists would be mentioned. Different shapes and dimensions were simulated/tested to achieve the increase of the $\%$ of molten metal usage in the mould, which means faster production rate and also savings during the production.

The mesh created for simulation of the final version was larger than in the previous versions to assure the very good simulation results. The size of each cell was set to $2,5 \mathrm{~mm}$, which resulted in 2510300 mould cells from which 200000 are the metal cells (castings, gating system and Connor inlets). The part of the mesh is shown on Fig. 7 [3].

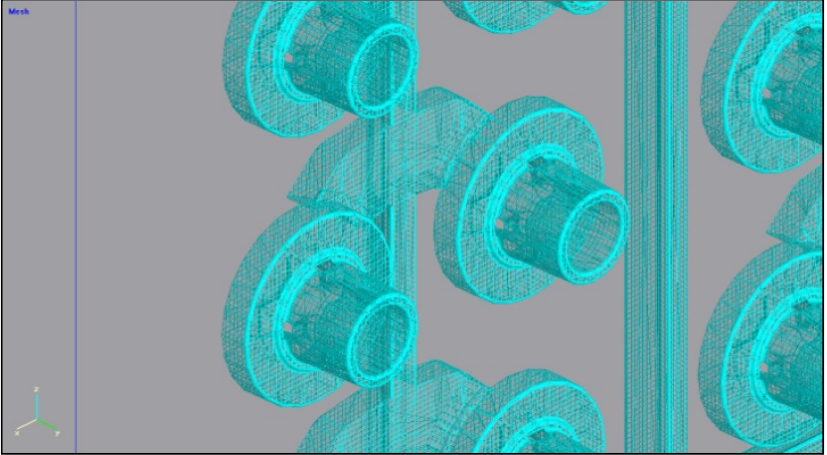

Fig. 7. Part of the mesh created for final version

After the solidification simulation, results of liquid phase and shrinkage were obtained. In this version, the last part of molten metal solidified in the Connor inlets, what is very suitable as it means that the hot spots are now located in the Connor inlets instead of in castings. On the Fig. 8 is pictured the last portion of liquid metal.

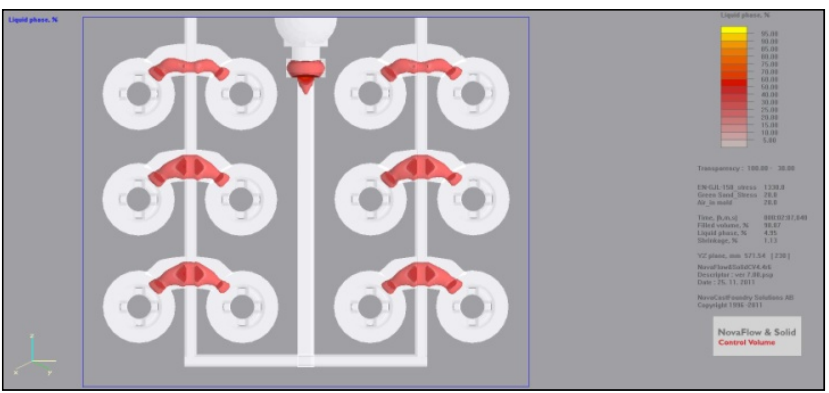

Fig. 8. Last portion of liquid metal during solidification

As the hot spots are located in Connor inlets, it is a good predictor that the shrinkage will also be located in the Connor inlets and not in the castings. As it is clear from the Fig. 9, castings solidified soundly and the shrinkage is located in the Connor inlets. The red places on the picture represent the shrinkage.

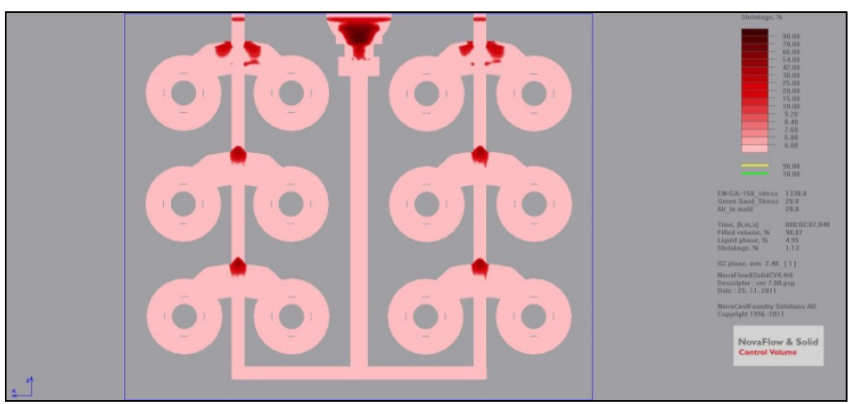

Fig. 9. Location of shrinkage after solidification

On Fig. 10 is pictured the cross-section of real casting proving that shrinkage does not occur in the castings. There is also shown that in the connection of casting and Connor inlet no shrinkage can be noticed as it was in the first version [4]. 


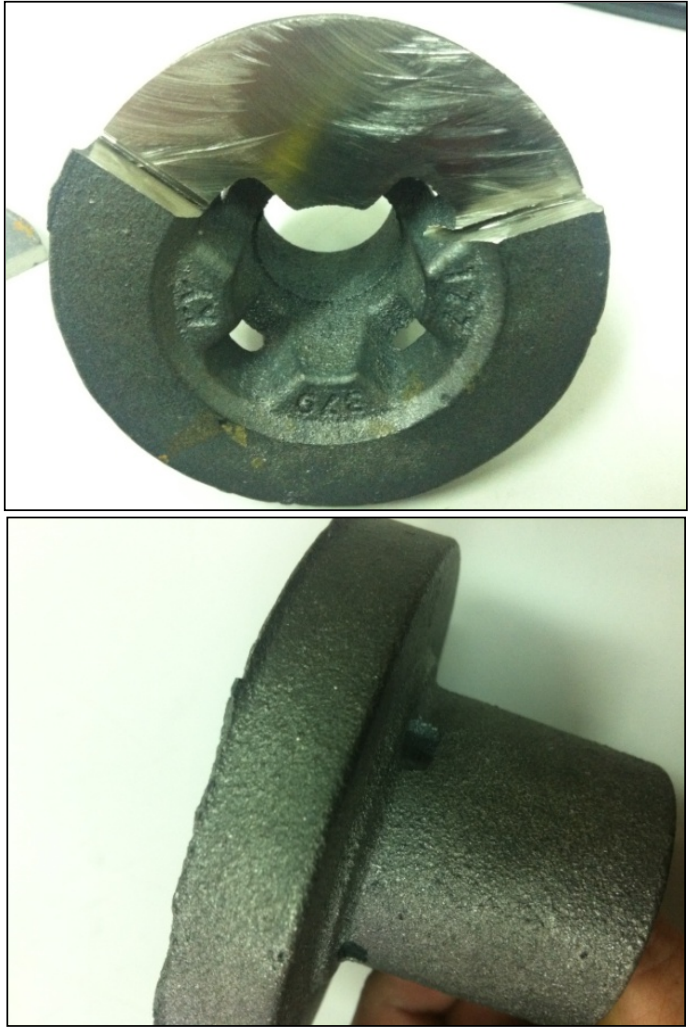

Fig. 10. No shrinkage in real castings

\section{Conclusion}

From all stated above, it can be mentioned that replacing the feeders with Connor inlets not only led to the elimination of porosity from the castings, which now solidify soundly without any defects, but it can be stated that there was an increase of $\%$ of molten metal usage. In the first version, the weight of the whole assembly is $16,5 \mathrm{~kg}$, which makes the \% of molten metal usage $55 \%$. On the other hand, the weight of the final proposed assembly using Connor inlets is $15 \mathrm{~kg}$, which makes $60 \%$ of molten metal usage.

It is clear that using of simulation software in the preproduction stage or for elimination of defects can play a great role in foundries. It not only saves a lot of time (production of sample castings and other changes to the model pattern), but it can also lead to great financial savings.

\section{Acknowledgements}

This work was financed by the Vedecká grantová agentúra MŠVVaŠ SR a SAV (VEGA), 1/0498/11.

\section{References}

[1] NovaFlow \& Solid CV. Manual, 2010.

[2] NOVACAST E-newsletter, No 1, June 2010.

[3] NOVACAST E-newsletter, No 2, December 2010.

[4] Herman, A. \& other (2000). Computer Simulation in Foundry, ČVUT, ISBN 80-01-02220 -X. 